\title{
3D-Printed Mucoadhesive Collagen Scaffolds as a Local Tetrahydrocurcumin Delivery System
}

\author{
Mireia Andonegi ${ }^{1}\left(\mathbb{D}\right.$, Teresa Carranza ${ }^{2}$, Alaitz Etxabide ${ }^{1} \mathbb{D}$, Koro de la Caba ${ }^{1,3, * \mathbb{D}}$ and Pedro Guerrero ${ }^{1,3,4, *(\mathbb{D})}$ \\ 1 BIOMAT Research Group, Escuela de Ingeniería de Gipuzkoa, University of the Basque Country (UPV/EHU), \\ Plaza de Europa 1, 20018 Donostia-San Sebastián, Spain; mireia.andonegui@ehu.eus (M.A.); \\ alaitz.etxabide@ehu.eus (A.E.) \\ 2 Domotek SL, B ${ }^{\circ}$ Santa Luzi 17, 20400 Tolosa, Spain; teresa@domotek.es \\ 3 BCMaterials, Basque Center for Materials, Applications and Nanostructures, UPV /EHU Science Park, \\ 48940 Leioa, Spain \\ 4 Proteinmat Materials SL, Avenida de Tolosa 72, 20018 Donostia-San Sebastian, Spain \\ * Correspondence: koro.delacaba@ehu.eus (K.d.l.C.); pedromanuel.guerrero@ehu.eus (P.G.)
}

Citation: Andonegi, M.; Carranza, T.; Etxabide, A.; de la Caba, K.; Guerrero, P. 3D-Printed Mucoadhesive Collagen Scaffolds as a Local

Tetrahydrocurcumin Delivery System. Pharmaceutics 2021, 13, 1697.

https://doi.org/10.3390/

pharmaceutics13101697

Academic Editor: Paola Russo

Received: 19 September 2021

Accepted: 13 October 2021

Published: 15 October 2021

Publisher's Note: MDPI stays neutral with regard to jurisdictional claims in published maps and institutional affiliations.

Copyright: (c) 2021 by the authors. Licensee MDPI, Basel, Switzerland. This article is an open access article distributed under the terms and conditions of the Creative Commons Attribution (CC BY) license (https:// creativecommons.org/licenses/by/ $4.0 /)$.

\begin{abstract}
Native collagen doughs were processed using a syringe-based extrusion 3D printer to obtain collagen scaffolds. Before processing, the rheological properties of the doughs were analyzed to determine the optimal 3D printing conditions. Samples showed a high shear-thinning behavior, reported beneficial in the 3D printing process. In addition, tetrahydrocurcumin (THC) was incorporated into the dough formulation and its effect on collagen structure, as well as the resulting scaffold's suitability for wound healing applications, were assessed. The denaturation peak observed by differential scanning calorimetry (DSC), along with the images of the scaffolds' surfaces assessed using scanning electron microscopy (SEM), showed that the fibrillar structure of collagen was maintained. These outcomes were correlated with X-ray diffraction (XRD) results, which showed an increase of the lateral packaging of collagen chains was observed in the samples with a THC content up to $4 \%$, while a higher content of THC considerably decreased the structural order of collagen. Furthermore, physical interactions between collagen and THC molecules were observed using Fourier transform infrared (FTIR) spectroscopy. Additionally, all samples showed swelling and a controlled release of THC. These results along with the mucoadhesive properties of collagen suggested the potential of these THC-collagen scaffolds as sustained THC delivery systems.
\end{abstract}

Keywords: native collagen; 3D printing; sustained release

\section{Introduction}

In recent decades, biofabrication of tissue constructs with hierarchical architecture has acquired special interest in tissue engineering and regenerative medicine as biological substitutes that can assist and promote the tissue healing process, providing the optimum conditions for the re-establishment of the damaged tissue [1]. In that way, different biofabrication methods have been developed, such as freeze-drying, electrospinning, and microengineering. However, due to the complex geometry of native tissues, these methods have shown limited reproducibility and versatility in the fabrication procedures [2]. More recently, 3D printing has emerged as a novel biofabrication method, characterized by a computer-based control that provides the addition of material, layer by layer, to obtain constructs with specific shapes [3]. 3D printing offers automated material deposition with spatial control and high reproducibility, which allows for the recreation of preprogrammed 3D tissue constructs, with personalized characteristics that mimic the patient-specific architecture and, consequently, the function of targeting tissues [4]. In addition, the technology and the low temperature used in 3D printing provide the potential to create scaffolds based on biopolymeric hydrogels with controlled placement of living cells [5], drugs [6], and/or bioactive molecules [7]. 
Collagen hydrogels have numerous attractive features for use as tissue engineering scaffold materials. Collagen is the main structural protein in the extracellular matrix (ECM) of mammalians and is a major determinant of the architecture and strength of many tissues [8]. Besides, collagen participates in numerous physiological interactions through its specific cell-binding sites, where the cell attachment, proliferation, migration, growth, and differentiation are the most significant $[9,10]$. Thus, collagen scaffolds have been used for tissue engineering due to their hemostatic, low antigenic, biodegradable, and biocompatible properties [11,12]. However, the resulting scaffolds offer poor mechanical properties and structural stability [13]. Hence, different strategies have been used to overcome these limitations on the overall integrity of printed collagen, incorporating additives that induce physical or chemical crosslinking [14].

Concerning additive incorporation, thetrahydrocurcumin (THC) can be incorporated into printable collagen formulations to obtain active hydrogels for wound healing. THC is a plant-derived compound obtained from the hydrogenation of curcumin that has attracted special interest in the pharmaceutical and cosmetic industries $[15,16]$. Due to the poor solubility in water, low absorption from the gut, rapid metabolism, and rapid systemic elimination of curcumin, its health benefits are limited [17]. Likewise, several studies have analyzed the antibacterial [18], antidiabetic [19], anticancer [20], and antiinflammatory activities [21] of THC metabolite using several drug-delivery systems, such as polymeric nanoparticles or capsules, solid lipid nanoparticles, liposomes, microemulsions, nanovesicles, and foams [22,23]. Furthermore, THC can be beneficial for local treatments, since it enhances collagen deposition, ECM accumulation, fibroblast growth, vascular density, and angiogenesis, contributing to faster wound healing [24].

Collagen hydrogels are printable if low concentrations, usually lower than $10 \mathrm{mg} / \mathrm{mL}$ [25], are used. In contrast to the usual use of these low collagen concentrations $(\approx 2 \mathrm{mg} / \mathrm{mL})$, in this study THC-collagen scaffolds were obtained by 3D printing using concentrated collagen solutions $(200 \mathrm{mg} / \mathrm{mL})$. Therefore, the optimization of the 3D-printing process, based on rheological analysis, had to be performed. It is worth noting that the use of crosslinkers was not needed since native collagen with no chemical pretreatment was used and, thus, the collagen triple helix structure was maintained. On the other hand, to analyze the effect of different THC concentrations on the scaffolds, physicochemical, thermal, morphological, and barrier properties of 3D-printed scaffolds were assessed. With the aim of a potential use of these scaffolds for wound healing applications, the mucoadhesive properties of the scaffolds were also evaluated.

\section{Materials and Methods}

\subsection{Materials}

Porcine collagen was supplied by Tenerias Omega (Navarre, Spain) and tetrahydrocurcumin (THC) was gifted by Sabinsa Corporation (East Windsor, NJ, USA).

\subsection{Mixture Preparation}

Native collagen was obtained according to the method of Andonegi et al. [26]. Firstly, porcine skins were defatted by immersion into $1 \mathrm{M} \mathrm{NaOH}$ solution for $12 \mathrm{~h}$ and then, neutralized in phosphate buffer saline (PBS) solution $(\mathrm{pH}=7.4)$. Afterwards, collagen was ground and freeze-dried to facilitate the subsequent processing. After this treatment, $2.5 \mathrm{~g}$ of collagen, THC $(0,2,4,6 \mathrm{wt} \%$ based on dry collagen) and $0.5 \mathrm{M}$ acetic acid (1:5 collagen/acetic acid ratio) were mixed using an ultra-turrax T25 (IKA, Staufen, Germany) until homogeneous pastes were achieved. The mixing process ( $2000 \mathrm{rpm}, 2 \mathrm{~min}$ ) was carried out in a cold bath to prevent the dough from heating up. Finally, the mixtures were stored in light-protected syringes at $4 \pm 1{ }^{\circ} \mathrm{C}$ until use. Four systems were produced and designated as Control, THC2, THC4, and THC6, as a function of THC content, $0,2,4$, and $6 \mathrm{wt} \%$, respectively. 


\subsection{Rheological Evaluation}

The viscoelastic properties of THC-collagen mixtures were studied at $35{ }^{\circ} \mathrm{C}$ by a Thermo Scientific Haake Rheostress1 Rheometer (IFI S.L., Vigo, Spain), equipped with a serrated plate-plate geometry (diameter of $35 \mathrm{~mm}$ ). The gap between plates was $1 \mathrm{~mm}$. Firstly, strain sweep tests were carried out at a constant frequency of $1 \mathrm{~Hz}$ and between $0.01 \%$ and $100 \%$ strain to determine the linear viscoelastic range (LVR) and the critical strain of the LVR. Subsequently, the frequency sweep test at a strain within the LVR range was carried out between 0.01 and $50 \mathrm{~Hz}$ to obtain loss tangent $(\tan \delta)$, elastic $\left(G^{\prime}\right)$, and viscous $\left(G^{\prime \prime}\right)$ moduli. Finally, the shear flow test was carried out in the shear rate $(\dot{\gamma})$ range from $0.1-50 \mathrm{~s}^{-1}$ using the same probe and gap. Samples were left running for $5 \mathrm{~min}$ before the test started to stabilize temperature and allow residual stress to relax.

The obtained flow data were fitted to the Williamson model for shear-thinning materials:

$$
\eta=\frac{\eta_{0}}{1+(\mathrm{k} \cdot \dot{\gamma})^{(1-n)}}
$$

where $\eta$ is the viscosity, $\eta_{0}$ is the limiting viscosity at low shear rate, $k$ is the consistency coefficient, and $\mathrm{n}$ is a flow index [27].

Additionally, a master curve of flow rate was obtained in order to describe the flow behavior of the doughs. A time-concentration superposition was made; first, using a vertical shift, given by normalization with the $\eta_{0}$ value of each dough; then, a horizontal shift specified by a time-concentration factor, $a_{c}$ [28]. Finally, the master curve was fitted to Williamson's model:

$$
\eta=\frac{\eta_{0}}{1+\left(\mathrm{k} \cdot \mathrm{a}_{\mathrm{c}} \cdot \dot{\gamma}\right)^{(1-n)}}
$$

Moreover, the flow behavior of collagen doughs at the 3D-printing conditions used can be assessed by the Weissenberg-Rabinowitsch equation:

$$
\gamma_{{ }_{\mathrm{w}}}=\gamma_{{ }_{\mathrm{wN}}} \frac{(3 n+1)}{4 n}
$$

where $n$ is the flow index, $\dot{\gamma}_{\mathrm{w}}$ is the shear rate at the wall, $\dot{\gamma}_{\mathrm{wN}}=(8 \mathrm{~V} / \mathrm{D})$ is the nominal shear rate, $\mathrm{V}$ is the average inlet velocity of the fluid, and $\mathrm{D}$ is the nozzle diameter [29].

\section{4. $3 D$ Printing}

Cura (Ultimaker Cura 4.6.1 Software, Utrecht, The Netherlands) was used to design the scaffolds as cylindrical mesh ( $21 \mathrm{~mm}$ diameter; $0.9 \mathrm{~mm}$ height) with infill of $75 \%$ ( $340 \mu \mathrm{m}$ pore diameter). Collagen scaffolds were fabricated at a printing temperature of $35^{\circ} \mathrm{C}$ using a syringe-based extrusion 3D DomoBIO printer (Domotek, Tolosa, Spain). The $3 \mathrm{D}$ printing speed was set at $3 \mathrm{~mm} / \mathrm{s}$ through a G18 nozzle with an inner diameter of $0.84 \mathrm{~mm}$. The temperature of the 3D-printer bed was fixed at $25^{\circ} \mathrm{C}$ with a layer height of $0.3 \mathrm{~mm}$. No post-processing treatment was carried out. All samples were left to dry and conditioned in a climatic chamber at $25{ }^{\circ} \mathrm{C}$ and $50 \%$ relative humidity before testing.

\subsection{Fourier Transform Infrared (FTIR) Spectroscopy}

Fourier transform infrared (FTIR) spectra were performed by using a Nicolet 380 FTIR spectrometer (Nicolet Instrument, Barcelona, Spain) equipped with attenuated total reflectance (ATR) crystal (ZnSe). A total of 32 scans were carried out at $4 \mathrm{~cm}^{-1}$ resolution.

\subsection{Differential Scanning Calorimetry (DSC)}

DSC measurements were performed by a Mettler Toledo DSC 822 (Mettler Toledo, Barcelona, Spain). Samples ( $3 \mathrm{mg}$ ) were put into sealed aluminium pans, to prevent mass loss, and subjected to a heating ramp from $25^{\circ} \mathrm{C}$ to $250{ }^{\circ} \mathrm{C}$ at a rate of $10^{\circ} \mathrm{C} / \mathrm{min}$, under nitrogen atmosphere to avoid oxidation. 


\subsection{X-ray Diffraction (XRD)}

XRD measurements were performed by a diffraction unit PANalytical Xpert PRO (PANalytical BV, Almelo, The Netherlands), operating at $40 \mathrm{kV}$ and $40 \mathrm{~mA}$. The radiation was generated from a $\mathrm{Cu}-\mathrm{K} \alpha(\lambda=1.5418 \AA)$ source. The diffraction data were collected from $2 \theta$ values from $2^{\circ}$ to $50^{\circ}$, where $\theta$ is the angle of incidence of the $X$-ray beam on the sample.

\subsection{Scanning Electron Microscopy (SEM)}

Scaffolds were placed on a metal stub and coated with gold using a JEOL fine-coat ion sputter JFC-1100 (JEOL Ltd., Tokyo, Japan), under argon atmosphere. Samples were observed using a Hitachi S-4800 scanning electron microscope (Hitachi, Madrid, Spain) at $15 \mathrm{kV}$ accelerating voltage.

\subsection{Ultraviolet-Visible (UV-Vis) Spectroscopy and THC Release}

The light-barrier properties were determined using a UV-Vis Multiskan SkyHigh (Thermo Fisher, Madrid, Spain) spectrophotometer to measure the light absorption at wavelengths ranging from 200 to $800 \mathrm{~nm}$.

UV-Vis spectroscopy was used to determine the THC release in PBS solution $(\mathrm{pH}=7.4)$. Firstly, the wavelength of maximum absorbance for THC in PBS was measured $\left(\lambda_{\max }=280 \mathrm{~nm}\right)$ and then, standard THC solutions were prepared over a concentration range of 3.906-1000 ppm to establish a calibration curve $\left(y=0.0004 x+0.0683 ; R^{2}=0.9635\right)$.

THC release was determined by immersing the scaffolds into PBS solution $(10 \mathrm{~mL})$ at room temperature for $2 \mathrm{~d}$. Aliquots $(3 \mathrm{~mL})$ were withdrawn at specific times $(4,6,8,24,30$, and $48 \mathrm{~h}$ ), replaced with fresh buffer and analyzed by UV-Vis spectroscopy at $280 \mathrm{~nm}$. All tests were carried out in triplicate for each composition.

The THC release data were kinetically evaluated by Korsmeyer-Peppas model:

$$
\frac{\mathrm{M}_{\mathrm{t}}}{\mathrm{M}_{\infty}}=\mathrm{k} t^{n}
$$

where $\mathrm{M}_{t} / \mathrm{M}_{\infty}$ is the fraction of drug released at time $t$ and $\mathrm{k}$ is Korsmeyer-Peppas constant related to the properties of the delivery system, such as structural and geometric properties. $n$ is the release exponent that shows the THC release mechanism: $n<0.45$, a pseudo-Fickian diffusion mechanism; $n=0.45$ a Fickian mechanism; $0.45<n<0.89$, an anomalous diffusion mechanism; and $n=0.89$, a non-Fickian diffusion mechanism [30].

\subsection{Water Uptake (WU)}

Scaffolds were weighed $\left(\mathrm{w}_{\mathrm{i}}\right)$ and then immersed into PBS $(\mathrm{pH}=7.4)$. Samples were reweighed at specific times $\left(\mathrm{w}_{\mathrm{t}}\right), 0,15,30,45,60,90,120,180,240,300,360,420,480,540$, 1440 , and $1800 \mathrm{~min}$, until constant values were achieved. The water uptake was calculated as:

$$
\mathrm{WU}(\%)=\frac{\mathrm{W}_{\mathrm{t}}-\mathrm{W}_{\mathrm{i}}}{\mathrm{W}_{\mathrm{i}}} \times 100
$$

Measurements were carried out for three specimens of each sample.

\subsection{In Vitro Mucoadhesion Study}

Mucoadhesive properties of collagen scaffolds were determined using TA.XT.Plus C Texture Analyzer (Aname Instrumentación Científica, Madrid, Spain), equipped with a $5 \mathrm{~kg}$ load cell and a $3.5 \mathrm{~mm}$ diameter cylinder probe. Type II mucin from porcine stomach (Sigma-Aldrich, Madrid, Spain) was used as a biological substrate. Before testing, a filter paper was hydrated by immersion into a PBS solution of type II mucin (1.0 $\mathrm{wt} \%$ ) for $5 \mathrm{~min}$ at $37^{\circ} \mathrm{C}$.

The excess surface liquid was withdrawn and then the substrate was horizontally kept on the cylindrical probe. Samples of each formulation were packed into cylindrical vessels (15 mm diameter) and placed on an upper cylinder probe lowered at a constant speed of 
$1 \mathrm{~mm} / \mathrm{s}$ until the mucoadhesive surface was reached. After keeping a contact time of $30 \mathrm{~s}$ under a force of $0.2 \mathrm{~N}$, the probe with the attached sample was removed at a constant rate $(1 \mathrm{~mm} / \mathrm{s})$. Texture Exponent 32 software was used to determine the maximum detachment force $\left(\mathrm{F}_{\max }\right)$ and the work of adhesion $\left(\mathrm{W}_{\mathrm{adh}}\right)$. All measurements were performed with at least five replicates.

\subsection{Statistical Analysis}

To determine significant differences between samples, analysis of variance (ANOVA) was done with SPSS software (SPSS Statistic 25, IBM Corp., Armonk, NY, USA). Tukey's test with a statistically significance at the $p<0.05$ level was considered for multiple comparisons among different systems.

\section{Results and Discussion}

First of all, rheological behavior was analyzed to optimize the 3D-printing process of collagen scaffolds. Additionally, to study the effect of different THC concentrations, physicochemical, thermal, morphological and barrier properties of 3D-printed scaffolds were assessed. Finally, keeping in mind a suitable application of these scaffolds, their mucoadhesive properties were evaluated with the aim of providing relevant information to highlight the potential use of these scaffolds for wound healing.

\subsection{Rheological Properties}

The knowledge and control of rheological properties are of great relevance to analyze and design the 3D-printing process [31]. Hence, stress sweep, frequency sweep, and flow tests were performed to analyze rheological properties before 3D printing. First, stress sweep tests were performed to determine the linear viscoelastic range (LVR) of THC-collagen doughs and then, frequency sweet tests were carried out within the LVR. The results are shown in Figure 1a. A predominant elastic behavior was observed in all samples since the storage modulus $\left(G^{\prime}\right)$ was greater than the loss modulus $\left(G^{\prime \prime}\right)$ in the studied interval [32]. Additionally, small dependence on frequency was observed in the loss modulus, while the storage modulus remained nearly constant, demonstrating the system stability. It is worth noting that the collagen network structure did not collapse, since no crossover point between $G^{\prime}$ and $G^{\prime \prime}$ was observed. This behavior followed the typical response of protein-based hydrogels observed in several studies [33,34]. Furthermore, the hydrogel behavior did not show noteworthy differences with the addition of THC, since similar $\tan \delta\left(G^{\prime \prime} / G^{\prime}\right)$ values were obtained for all the formulations. Likewise, the dough printability can be assessed in terms of the minimum pressure required and modelled using the loss tangent. The loss tangent values found in this study ranged from 0.15 to 0.40 , in accordance with other studies that suggested good printability within loss tangent values from 0.25 to 0.45 [14]. 


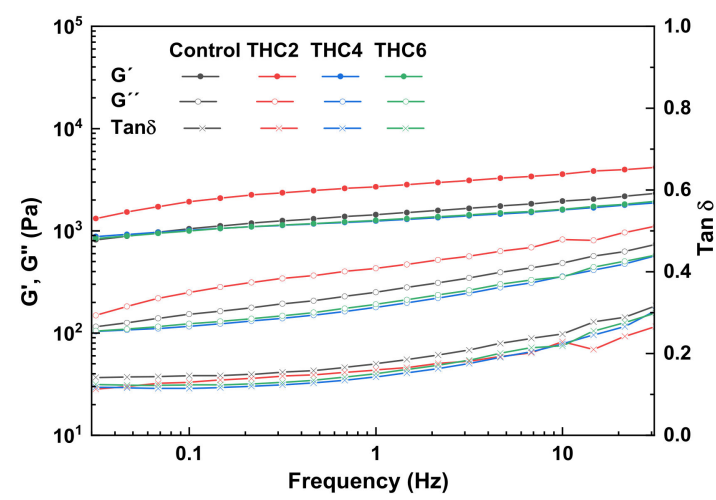

(a)

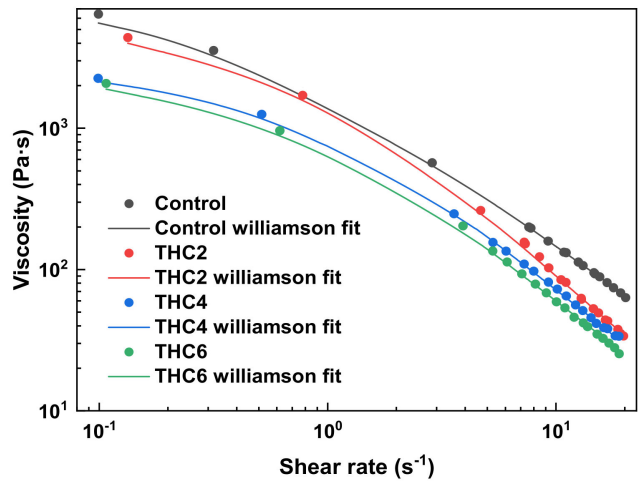

(b)

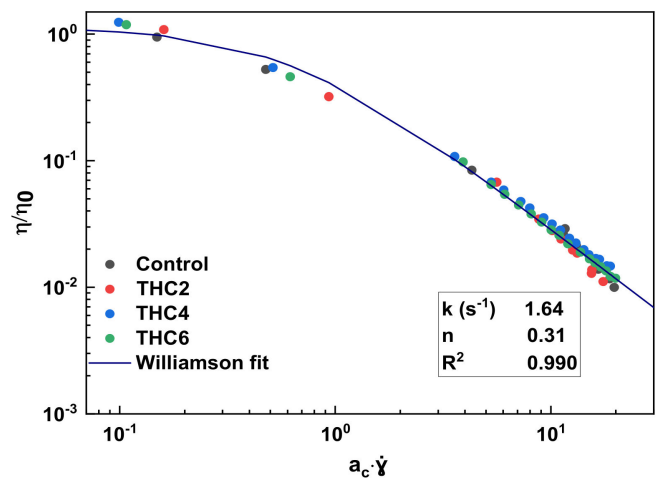

(c)

Figure 1. (a) Storage moduli $\left(G^{\prime}\right)$, loss moduli $\left(G^{\prime \prime}\right)$, and loss tangent (tan $\left.\delta\right)$, obtained through frequency sweep test for collagen doughs; (b) Flow curves of collagen doughs, fitted by Williamson model; and (c) Master flow curve for collagen doughs fitted by Williamson model, after performing a THC concentration-dependent shift $\left(\eta_{0}, a_{c}\right)$ using the control sample as reference.

The viscosity suitable for 3D printing must be low enough to permit easy extrusion through the nozzle and high enough to be cohesive with the previously deposited layer while maintaining the shape [35]. Therefore, the flow behavior of THC-collagen samples was analyzed and the dependence of apparent viscosities on shear rate is shown in Figure 1b. All samples displayed similar steady-state viscosity ( $\eta$ ) pattern of nonNewtonian fluids with a shear-thinning behavior and a tendency to reach a Newtonian region at a low shear rate (Newtonian plateau zone); thus, zero-shear viscosity $\left(\eta_{0}\right)$ was estimated [36]. Zero-shear viscosity is the viscosity when the material is at rest; this is a limiting value that cannot be measured directly and must be estimated by extrapolation, fitting the data to the model. The experimental flow data obtained were satisfactorily fitted $\left(\mathrm{R}^{2}>0.996\right)$ to the Williamson model (Equation (1) and the resulting fit parameters are shown in Table 1. The shear-thinning performance indicated that collagen chains were affected by the shear stress between the layers when the flow rate increased, thereby reducing the force between them [37]. This behavior was reported beneficial in the 3D-printing process for solid-like materials to be extruded through the nozzle [28,38]. As can be seen in Table 1 , all samples showed relatively low flow index values $(n<0.42)$, corroborating the shear-thinning behavior of the samples [39]. Furthermore, the decrease of $\eta_{0}$ with the increase of THC concentration denoted the establishment of a lower number of links between collagen and THC molecules [40]. 
Table 1. Parameters of Williamson model, master curve shift factors, and shear rate values for collagen doughs.

\begin{tabular}{ccccccc}
\hline Sample & $\left.\boldsymbol{\eta}_{\mathbf{0}} \mathbf{( P a} \cdot \mathbf{s}^{-\mathbf{1}}\right)$ & $\mathbf{k}\left(\mathbf{s}^{-\mathbf{1}}\right)$ & $\boldsymbol{n}$ & $\mathbf{R}^{\mathbf{2}}$ & $\mathbf{a}_{\mathbf{c}}$ & $\dot{\gamma}_{\mathbf{w}}$ \\
\hline Control & 6764 & 2.71 & 0.15 & 0.996 & 1 & 69.05 \\
THC2 & 4402 & 1.51 & 0.42 & 0.989 & 0.80 & 38.43 \\
THC4 & 2298 & 1.37 & 0.31 & 0.996 & 0.67 & 44.47 \\
THC6 & 2083 & 1.57 & 0.28 & 0.997 & 0.67 & 46.94 \\
\hline
\end{tabular}

As all samples showed a similar tendency in the shear-thinning region, curves could be fitted to a single master curve (Figure 1c). The shift factor $\left(a_{c}\right)$ was calculated and included in Table 1 , where $a_{c}=1$ was assigned to the control sample. A decrease of $a_{c}$ from 1 to 0.67 in THC4 and THC6 doughs indicated a higher consistency when the THC content increased [28]. Therefore, the relatively small $\tan \delta$ and the low viscosity observed at high shear rates suggested that the THC-collagen doughs would be easily extruded by the syringe with a high shear rate at the nozzle tip [41].

For a further assessment of the flow behavior of collagen doughs in the 3D-printing process, the shear rate in the nozzle tip was calculated (Equation (3) and the values are shown in Table 1. Once the flow curves were obtained and the shear-thinning behaviour observed, high shear rate values were selected since, under these conditions, the material offers less resistance (lower viscosity) and flows better. As the flow index (n) of the master curve was obtained by fitting data to the Williamson model, the printing velocity could be obtained using the equation of Weissenberg-Rabinowitsch (Equation (3). 3D-printed scaffolds are shown in Figure 2.
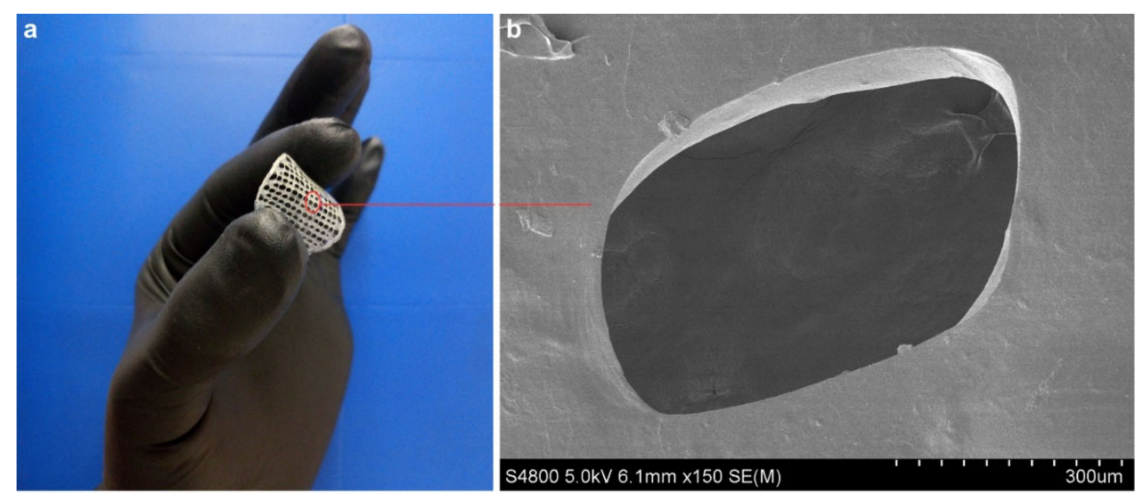

Figure 2. (a) A 3D printed THC6 scaffold; and (b) SEM image of THC6 surface.

\subsection{Physicochemical and Thermal Properties}

To assess the interactions among the components of the scaffold formulation, FTIR analysis was carried out and FTIR spectra are shown in Figure 3.

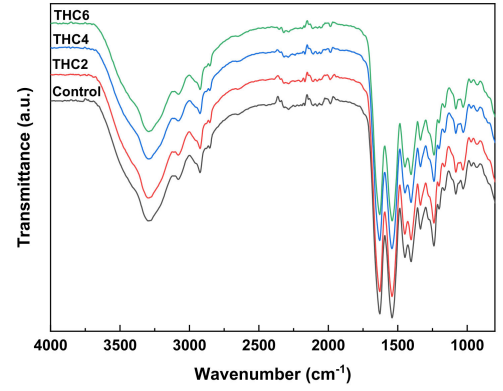

(a)

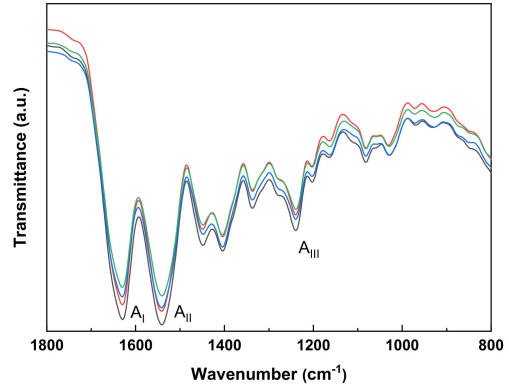

(b)

Figure 3. FTIR spectra of 3D-printed collagen scaffolds: (a) from 4000 to $750 \mathrm{~cm}^{-1}$; and (b) from 1800 to $750 \mathrm{~cm}^{-1}$. 
All the spectra showed the main absorption bands assigned to the peptide bonds in collagen: $\mathrm{N}-\mathrm{H}$ stretching vibration of amide $\mathrm{A}$ at $3287 \mathrm{~cm}^{-1}, \mathrm{C}=\mathrm{O}$ stretching of amide I at $1630 \mathrm{~cm}^{-1}, \mathrm{~N}-\mathrm{H}$ bending of amide II at $1540 \mathrm{~cm}^{-1}$, and C-N stretching of amide III at $1240 \mathrm{~cm}^{-1}$ [42]. The amide $\mathrm{A}$ band is commonly observed in the wavenumber range of $3400-3440 \mathrm{~cm}^{-1}$ but, when the band position is shifted to a lower frequency, this shift indicates that $\mathrm{N}-\mathrm{H}$ groups in collagen are involved in hydrogen bonding (Figure 4), leading to stability in the collagen triple-helical structure [43]. Additionally, a change in the intensity of the amide bands was observed with the incorporation of THC, indicative of physical crosslinking. No more obvious changes were observed in FTIR spectra, suggesting the prevalence of collagen secondary structure after the mixture preparation and 3D-printing processes [44].

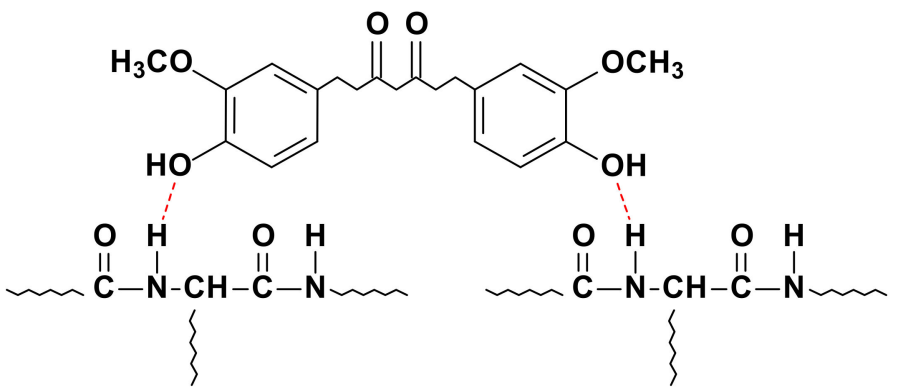

Figure 4. Schematic diagram of the interactions between collagen and THC by hydrogen bonding.

The thermal behavior of collagen scaffolds was studied using DSC analysis. As can be seen in Figure 5, all samples exhibited two endothermic peaks: the first peak, around $82{ }^{\circ} \mathrm{C}$, is related to the free and bound water release [45]; and the second peak, around $210^{\circ} \mathrm{C}$, is associated with collagen thermal denaturation process [46]. During this transition, collagen experienced conformational changes from triple helix to random coil and the structural water was released [47-49]. Therefore, it is worth noting that these values confirmed the prevalence of the triple helix structure of collagen after THC addition and 3D printing, as also observed by FTIR analysis. Additionally, samples with THC showed a small peak around $95{ }^{\circ} \mathrm{C}$, related to THC melting [23], and the enthalpy value increased with THC content.

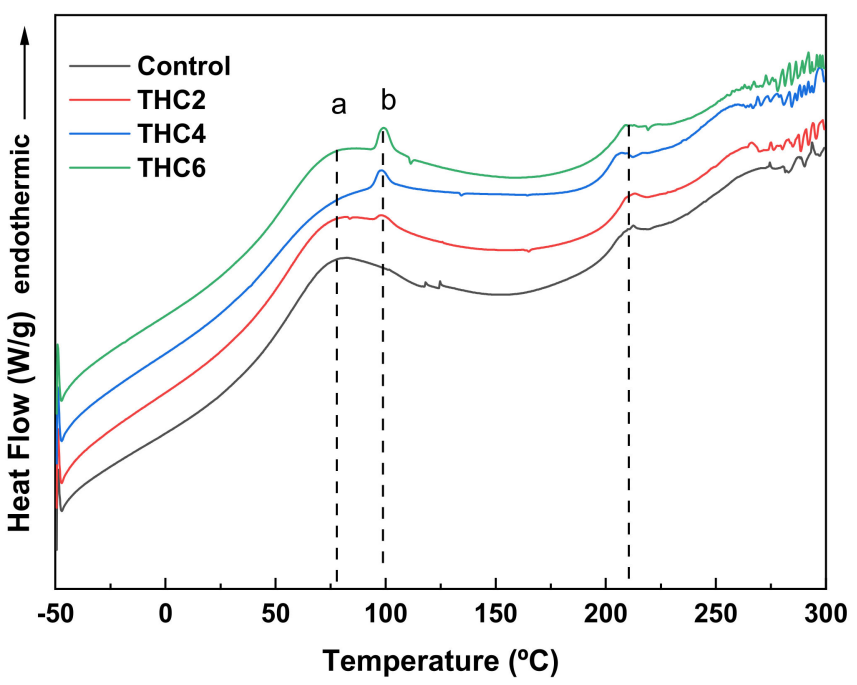

Figure 5. DSC thermograms of collagen scaffolds: (a) free and bound water release, (b) THC melting, and (c) collagen thermal denaturation. 


\subsection{Morphological and Barrier Properties}

For a further analysis of the effect of THC addition on collagen structure, XRD and SEM analyses were carried out. As for XRD analysis (Figure 6), all samples showed XRD patterns of nearly amorphous materials. The peak around $70^{\circ}$, related to the triple helix structure of collagen, represents the lateral packing distance between collagen chains [50] and the broad peak around $20^{\circ}$, associated with the diffuse scattering of collagen fibers, represents the amorphous structure of the samples [51]. Furthermore, the samples with THC showed the characteristic peaks of THC at $18^{\circ}$ and $24^{\circ}$ [15]. As can be seen, all samples showed similar XRD patterns, indicating the prevalence of the collagen structural order. When a higher THC content was added (THC6), the peak intensity at $7^{\circ}$ and $20^{\circ}$ decreased, suggesting the decrease of the structural order in collagen scaffolds.

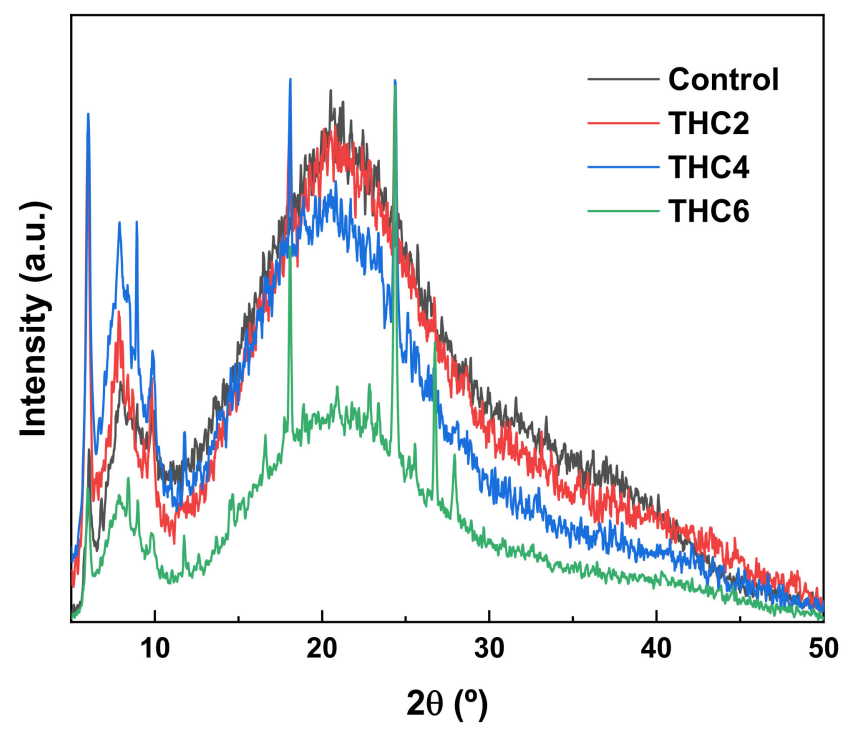

Figure 6. XRD patterns of collagen scaffolds.

To assess the morphology of 3D-printed scaffolds and ensure a good comprehension of the microstructure of the scaffold, SEM analysis was carried out and cross-section images are shown in Figure 7. SEM micrographs showed that all samples had a similar compact amorphous structure. When THC content increased from 4 to $6 \mathrm{wt} \%$, a less organized structure was observed, in accordance with XRD results. It is worth noting that 3D-printed layers cannot be differentiated, indicating their good adhesion.

Considering wound dressing as a feasible application of these scaffolds, light barrier properties were analyzed by UV-Vis spectroscopy. As can be seen in Figure 8, control samples showed the characteristic UV light barrier of collagen with an absorbance maximum from 200 to $250 \mathrm{~nm}$, associated with carbonyl, carboxyl and amide groups, and a small peak between 250 and $280 \mathrm{~nm}$, related to chromophores groups of tyrosine and phenylalanine amino acids $[52,53]$. The addition of THC showed a slight increase of the absorbance in the visible light range $(400-800 \mathrm{~nm})$ and a strong increase in the UV range (200-400 nm) due to the absorption peak of THC around $280 \mathrm{~nm}$ with a shoulder at $310 \mathrm{~nm}$ [54]. Furthermore, the increase of the absorbance around $210 \mathrm{~nm}$ may be related to the photo-oxidized THC [55]. Nevertheless, no relevant difference was observed among collagen scaffolds with THC. 


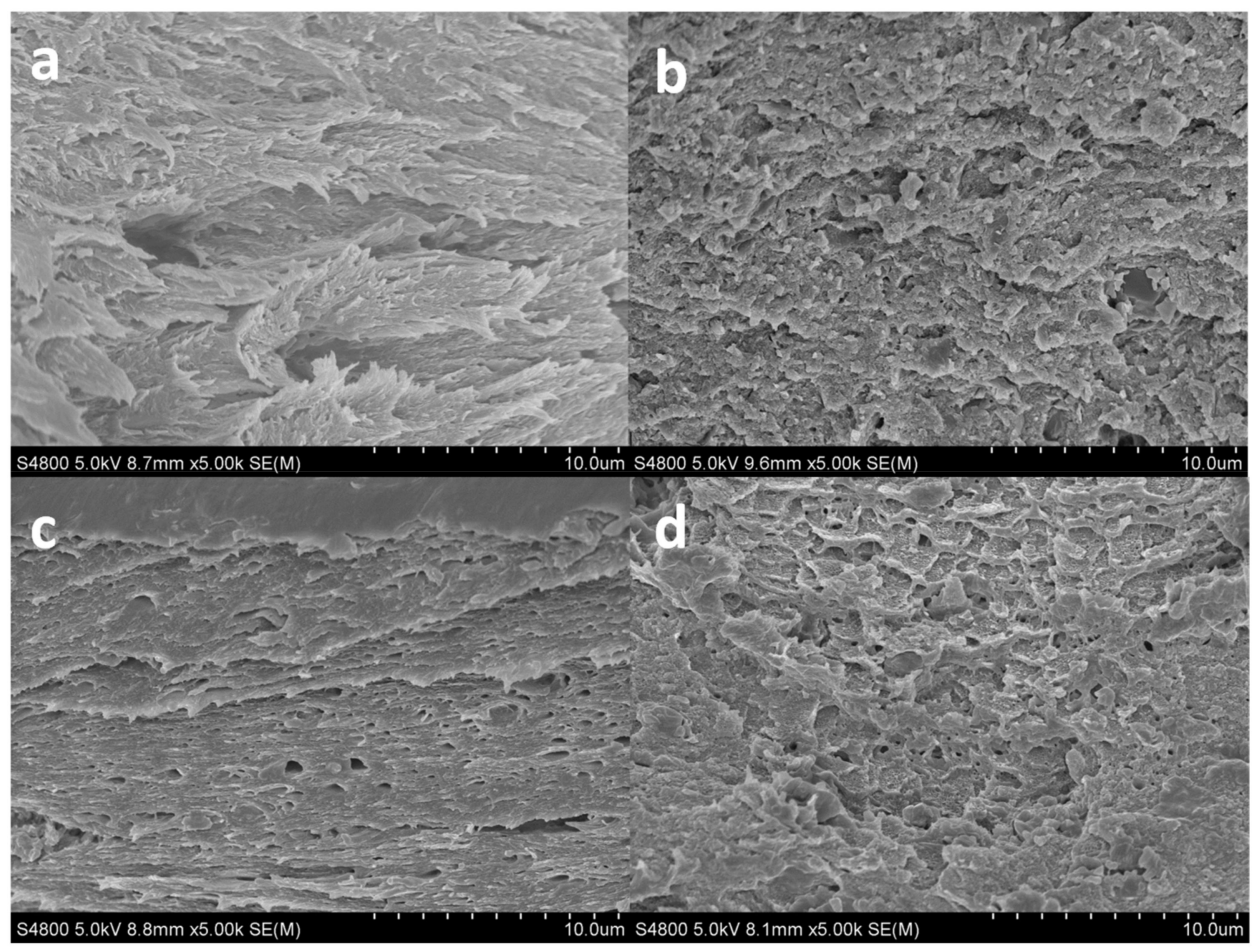

Figure 7. SEM images of the cross-section of collagen scaffolds: (a) control; (b) THC2; (c) THC4; and (d) THC6.

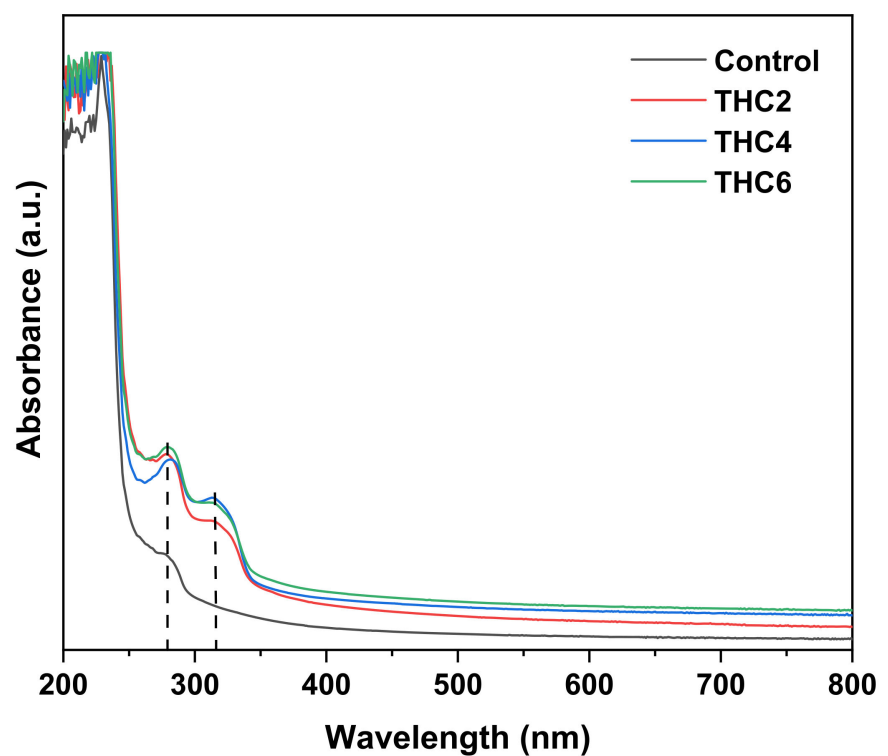

Figure 8. UV-Vis spectra of collagen scaffolds.

\subsection{Water Uptake (WU) and THC Release}

WU measurements were performed to determine the effect of THC on the water absorption capacity of the scaffolds. WU results showed the capacity of collagen scaffolds to hold a large number of water molecules. As can be observed in Figure 9a, THC concentration had no relevant effect on the WU capacity, which was around $600 \%$. The continuous growth of WU values occurred until $1880 \mathrm{~min}$, when the equilibrium was achieved. It is worth noting that scaffolds were stable and maintained integrity during the immersion period analyzed in this study. 


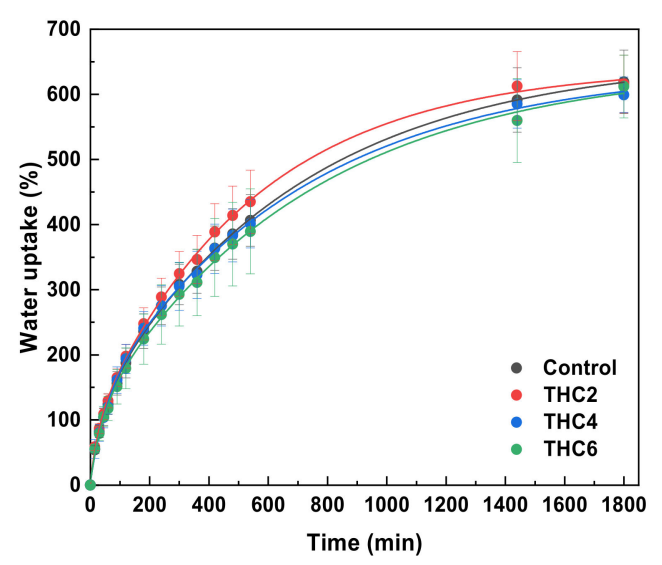

(a)

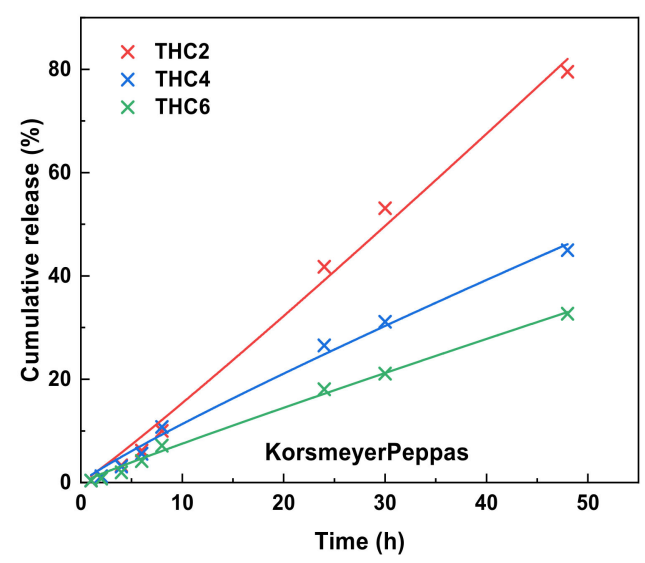

(b)

Figure 9. (a) Water uptake and (b) THC release from THC-collagen scaffolds (data fitted to Korsmeyer-Peppas model).

The release of THC from collagen scaffolds was assessed to determine the delivery trend. As can be observed in Figure 9b, all samples showed a sustained drug release, in which $82 \%, 45 \%$, and $33 \%$ of THC was released from THC2, THC4, and THC6, respectively. It is worth noting that no initial burst of drug release was observed, probably due to collagen-THC interactions by hydrogen bonding (Figure 4), as suggested by FTIR analysis, and due to the compact structure observed by SEM. In order to provide a more sustained release, THC6 scaffold could be preferred.

For a better understanding of the release mechanism, experimental THC release data were fitted to the Korsmeyer-Peppas model and the estimated kinetic parameters are summarized in Table 2. As can be seen, the release data were well-fitted to the KorsmeyerPeppas model, with $\mathrm{R}^{2}$ values higher than 0.9900 . The value of $n$ indicates the mechanism that describes how the active compound is released from the matrix. In this study, $n$ values were higher than 0.89 , indicating that the case II release mechanism controls the THC release [56]. These results are particularly interesting since case II release is purely controlled by the swelling of the hydrophilic glassy polymeric system through the relaxation of collagen chains, indicating that the drug transport mechanism is independent of time $[57,58]$.

Table 2. Parameters of Korsmeyer-Peppas model for THC release from collagen scaffolds.

\begin{tabular}{cccc}
\hline Sample & THC2 & THC4 & THC6 \\
\hline$k$ & 1.3227 & 1.4457 & 0.8651 \\
$n$ & 1.0660 & 0.8947 & 0.9406 \\
$\mathrm{R}^{2}$ & 0.9913 & 0.9900 & 0.9944 \\
\hline
\end{tabular}

\subsection{Mucoadhesive Properties}

Considering the potential application of these collagen scaffolds as a local treatment of wounds, a good adhesiveness is essential to immobilize the scaffold, which is the drug-delivery device, on a specific site for targeted release and optimal drug delivery. Mucoadhesion is defined as the adhesion between the polymer and the mucus and intimate contact between them must be formed for the occurrence of mucoadhesion [59]. In this study, mucoadhesive properties of wet collagen scaffolds in contact with type II mucin from porcine stomach were measured. The height of the peak is the maximum force $\left(F_{\max }\right)$ required to separate the probe from the mucin, while the total amount of forces involved in the probe withdrawal from the mucin is the work of adhesion $\left(W_{\mathrm{adh}}\right)$, calculated from the area under the force versus distance curve [60]. All the scaffolds investigated in this study showed positive adhesive forces and, therefore, some form of adhesion occurred between mucus and collagen. Representative load versus deformation curves for THC-collagen 
scaffolds are displayed in Figure 10. All the recordings from the tensile experiments showed a similar shape.

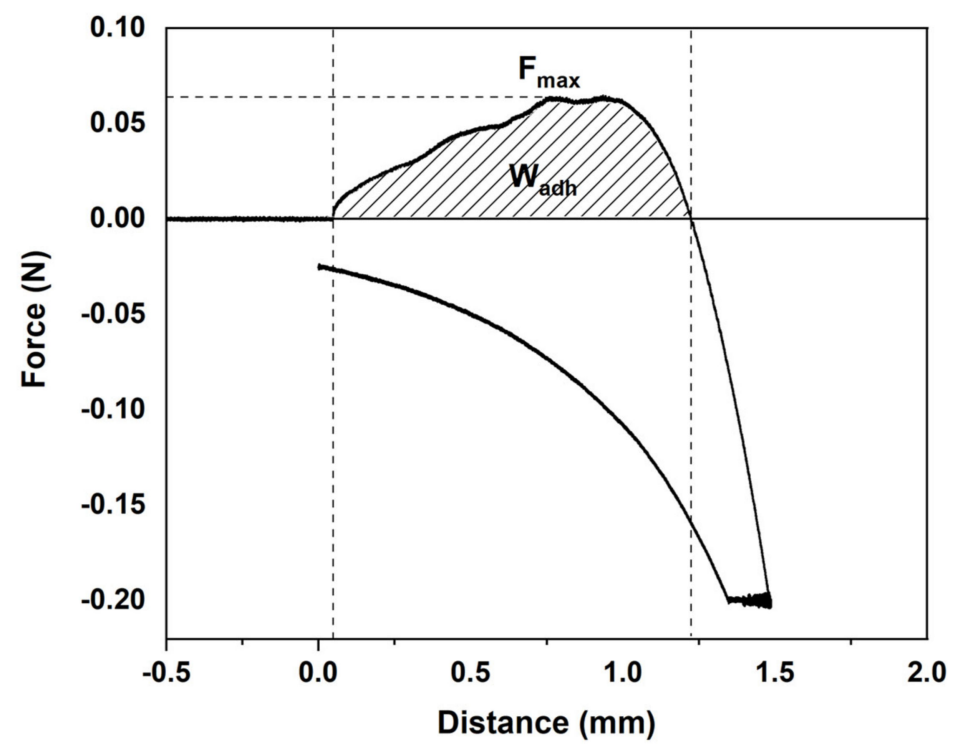

Figure 10. Characteristic load versus deformation curve for THC6 scaffolds.

The good mucoadhesive properties observed on all the samples is the result of the physical interactions among the mucin and collagen, mainly by hydrogen bonding and Van der Waals attraction. These forces are related to the amino acid residues in collagen that form hydrogen bonds with the glycoproteins in mucin [61]. Due to these weak interactions between collagen and mucus, fracture strengths were moderate. The forces produced were mainly due to either mechanical engulfment of the collagen by the mucus or by mechanical penetration of the mucus into collagen crevices. When fracture occurred, collagen almost "popped" out of the mucus layer, as if mucin was not bound to collagen. A failure occurred nearly at the same stage position as the point of initial contact.

As can be seen in Table 3, similar $(p>0.05) \mathrm{F}_{\max }$ and $\mathrm{W}_{\text {adh }}$ values were found. The incorporation of THC did not affect $F_{\max }$ and $W_{\text {adh }}$ values of collagen scaffolds. It is worth noting that different responses can be obtained depending on the analysis type used and the testing conditions employed [62]. Additionally, the mucoadhesive behavior of pure collagen has not been widely studied and, thus, data for comparison have not been found. Therefore, the results of this report should open new avenues of thought regarding the properties of bioadhesive candidates, although further work is needed to promote their application for wound healing.

Table 3. Mucoadhesive properties of collagen scaffolds in terms of the detachment force $\left(\mathrm{F}_{\max }\right)$ and the work of adhesion $\left(\mathrm{W}_{\mathrm{adh}}\right)$. Means followed by the same letter in the same column do not differ statistically among themselves by Tukey test $(p<0.05)$.

\begin{tabular}{ccc}
\hline Film & $\mathbf{F}_{\max }(\mathbf{N})$ & $\mathbf{W}_{\text {adh }} \mathbf{( N \cdot \mathbf { m m } )}$ \\
\hline Control & $0.0652 \pm 0.0035^{\mathrm{a}}$ & $0.0492 \pm 0.00304^{\mathrm{a}}$ \\
THC2 & $0.0672 \pm 0.0020^{\mathrm{a}}$ & $0.0475 \pm 0.00203^{\mathrm{a}}$ \\
THC4 & $0.0681 \pm 0.0020^{\mathrm{a}}$ & $0.0494 \pm 0.00303^{\mathrm{a}}$ \\
THC6 & $0.0699 \pm 0.0030^{\mathrm{a}}$ & $0.0485 \pm 0.00233^{\mathrm{a}}$ \\
\hline
\end{tabular}

\section{Conclusions}

Collagen scaffolds with controlled THC delivery and potential for local wound healing were developed by 3D printing. The samples were prepared with high collagen concentration $(200 \mathrm{mg} / \mathrm{mL})$ and rheological analysis showed suitable flow behavior to be 3D printed. Neither the addition of THC nor the 3D-printing conditions affected the triple helix 
structure of native collagen, as observed by SEM and XRD analyses, although physical interactions between collagen and THC were suggested by FTIR analysis. Furthermore, the high water-holding capacity of THC-collagen scaffolds, together with the sustained THC release and mucoadhesive properties, make these scaffolds potential candidates for wound-healing application. In this sense, the sample with $6 \mathrm{wt} \%$ THC could be preferred for a more sustained release of the bioactive. In future works, in vitro assays will be carried out to assess the scaffold stability in cell culture conditions as well as cell viability, adhesion, and spreading. Additionally, in vivo tests will be performed to show the therapeutic effect of these scaffolds and their potential in promoting wound healing processes.

Author Contributions: Conceptualization, K.d.l.C. and P.G.; methodology, T.C. and P.G.; formal analysis, M.A.; investigation, M.A., T.C., and A.E.; resources, K.d.l.C.; data curation, A.E. and P.G.; writing-original draft preparation, M.A.; writing—review and editing, T.C., A.E., K.d.l.C., and P.G.; supervision, K.d.l.C. and P.G.; project administration, K.d.l.C.; funding acquisition, K.d.1.C. All authors have read and agreed to the published version of the manuscript.

Funding: This research was funded by MCI/AEI/FEDER, UE (RTI2018-097100-B-C22) and Provincial Council of Gipuzkoa.

Institutional Review Board Statement: Not applicable.

Informed Consent Statement: Not applicable.

Data Availability Statement: Not applicable.

Acknowledgments: M.A. thanks the Basque Government (PRE_2017_1_0025) and A.E. thanks the State Research Agency of Spain within the Juan de la Cierva-Incorporation action (IJC2019-039697I). Thanks also to the Advanced Research Facilities (SGIker) from the UPV/EHU.

Conflicts of Interest: The authors declare no conflict of interest. The Domotek SL and Proteinmat materials SL companies had no role in the design of the study; in the collection, analyses, or interpretation of data; in the writing of the manuscript, and in the decision to publish the results.

\section{References}

1. Dhandayuthapani, B.; Yoshida, Y.; Maekawa, T.; Kumar, D.S. Polymeric Scaffolds in Tissue Engineering Application: A Review. Int. J. Polym. Sci. 2011, 2011, 19. [CrossRef]

2. Bao, G. Biofabrication in Tissue Engineering. In Racing for the Surface; Li, B., Moriarty, T., Webster, T., Xing, M., Eds.; Springer: Berlin/Heidelberg, Germany, 2020; pp. 289-312. [CrossRef]

3. Saptarshi, S.M.; Zhou, D.C. Basics of 3D Printing: Engineering Aspect. In 3D Printing in Orthopaedic Surgery; Dipola, M., Wodajo, F.M., Eds.; Elsevier: Berlin/Heidelberg, Germany, 2019; pp. 17-30. [CrossRef]

4. Zhang, Y.S.; Yue, K.; Aleman, J.; Moghaddam, K.M.; Bakht, S.M.; Yang, J.; Jia, W.; Dell’Erba, V.; Assawes, P.; Shin, S.R.; et al. 3D Bioprinting for Tissue and Organ Fabrication. Ann. Biomed. Eng. 2017, 45, 148-163. [CrossRef]

5. Armstrong, J.P.K.; Burke, M.; Carter, B.M.; Davis, S.A.; Perriman, A.W. 3D Bioprinting using a template porous bioink. Adv. Healthc. Mater. 2016, 5, 1724-1730. [CrossRef]

6. Chou, P.Y.; Chou, Y.C.; Lai, L.H.; Lin, Y.T.; Lu, C.J.; Liu, S.J. Fabrication of drug-eluting nano-hydroxylapatite filled polycaprolactone nanocomposites using solution-extrusion 3D printing technique. Polymers 2021, 13, 318. [CrossRef] [PubMed]

7. Tavares, M.T.; Gaspar, V.M.; Monteiro, M.; Farinha, J.P.S.; Baleizão, C.; Mano, J.F. GelMA/bioactive silica nanocomposite bioinks for stem cell osteogenic differentiation. Biofabrication 2021, 13, 035012. [CrossRef] [PubMed]

8. Yang, X.B.; Bhatnagar, R.S.; Li, S.; Oreffo, R.O.C. Biomimetic collagen scaffolds for human bone cell growth and differentiation. Tissue Eng. 2004, 10, 1148-1159. [CrossRef]

9. Hu, K.; Hu, M.; Xiao, Y.; Cui, Y.; Yan, J.; Yang, G.; Zhang, F.; Lin, G.; Yi, H.; Han, L.; et al. Preparation recombination human-like collagen/fibroin scaffold and promoting the cell compatibility with osteoblasts. J. Biomed. Mater. Res. Part A 2020, 108, $346-353$. [CrossRef]

10. Sorkio, A.E.; Vuorimaa-Laukkanen, E.P.; Hakola, H.M.; Liang, H.; Ujula, T.A.; Valle-Delgado, J.J.; Österberg, M.; Yliperttula, M.L.; Skottman, H. Biomimetic collagen I and IV double layer Langmuir-Schaefer films as microenvironment for human pluripotent stem cell derived retinal pigment epithelial cells. Biomaterials 2015, 51, 257-269. [CrossRef]

11. Li, Z.; Du, T.; Ruan, C.; Niu, X. Bioinspired mineralized collagen scaffolds for bone tissue engineering. Bioact. Mater. 2021, 6, 1491-1511. [CrossRef]

12. Ma, C.; Wang, H.; Chi, Y.; Wang, Y.; Jiang, L.; Xu, N.; Wu, Q.; Feng, Q.; Sun, X. Preparation of oriented collagen fiber scaffolds and its application in bone tissue engineering. Appl. Mater. Today 2021, 22, 100902. [CrossRef]

13. Włodarczyk-Biegun, M.K.; del Campo, A. 3D bioprinting of structural proteins. Biomaterials 2017, 134, 180-201. [CrossRef] 
14. Lee, J.M.; Suen, S.K.Q.; Ng, W.L.; Ma, W.C.; Yeong, W.Y. Bioprinting of collagen: Considerations, potentials and application, Macromol. Biosci. 2021, 21, 2000280. [CrossRef]

15. Rramaswamy, R.; Mani, G.; Venkatachalam, S.; Yasam, R.V.; Rajendran, J.C.B.; Tae, J.H. Preparation and characterization of tetrahydrocurcumin-loaded cellulose acetate phthalate/polyethylene glicol electrospun nanofibers. AAPS PharmSciTech 2018, 19, 7. [CrossRef] [PubMed]

16. Zhang, Z.B.; Luo, D.D.; Xie, J.H.; Xian, Y.F.; Lai, Z.Q.; Liu, Y.H.; Liu, W.H.; Chen, J.N.; Lai, X.P.; Lin, Z.X.; et al. Curmumin's metabolites, tetrahydrocurcumin and octahydrocurcumin, possess superior anti-inflammatory effect in vitro through suppression of TAK1-NF-kB Pathway. Front. Pharmacol. 2018, 9, 1181. [CrossRef]

17. Jäger, R.; Lowery, R.P.; Calvanese, A.V.; Joy, J.M.; Purpura, M.; Wilson, J.M. Comparative absorption of curcumin formulations. Nutr. J. 2014, 13, 11. [CrossRef]

18. Manjunatha, J.R.; Bettadaiah, B.K.; Negi, P.S.; Srinivas, P. Synthesis of quinolone derivates of tetrahydrocurcumin and zingerone and evaluation of their antioxidant and antibacterial attributes. Food Chem. 2013, 136, 650-658. [CrossRef]

19. Murugan, P.; Pari, L. Effect of tetrahydrocurcumin on lipod peroxidation and lipids in streptozotocin-nicotinamide-induced diabetic rats. Basic Clin. Pharmacol. Toxicol. 2006, 99, 122-127. [CrossRef]

20. Mahal, A.; Wu, P.; Jiang, Z.H.; Wei, X. Schiff bases of tetrahydrocurcumin as potential anticancer agents. ChemistrySelect 2019, 4, 366-369. [CrossRef]

21. Sandur, S.K.; Pandey, M.K.; Sung, B.; Ahn, K.S.; Murakami, A.; Sethi, G.; Limtrakul, P.; Badmaev, V.; Aggarwal, B.B. Curcumin, demethoxycurcumin, bisdemethoxycurcumin, tetrahydrocurcumin and turmerones differentially regulate anti-inflammatory and anti-proliferative responses through a ROS-independent mechanism. Carcinogenesis 2007, 28, 1765-1773. [CrossRef]

22. Kakkar, V.; Saini, K.; Saini, M.; Kumar, M.; Narula, P.; Duggal, I. Comparison of therapeutic efficacy of nanoformulations of curcumin vs tetrahydrocurcumin in various disorders. In Nanoformulations in Human Health; Talegaonkar, S., Rai, M., Eds.; Springer: Berlin/Heidelberg, Germany, 2020; Volume 17, pp. 377-401. [CrossRef]

23. Kakkar, V.; Kaur, I.P.; Kaur, A.P.; Saini, K.; Singh, K.K. Topical delivery of tetrahydrocurcumin nanoparticles effectively inhibits skin inflammation: In vitro and in vivo study. Drug Dev. Ind. Pharm. 2018, 44, 1701-1712. [CrossRef]

24. Rao, A.B.; Prasad, E.; Deepthi, S.S.; Haritha, V.; Ramakrishna, S.; Madhusudan, K.; Surekha, M.V.; Rao, Y.S.R.V. Wound healing: A new perspective on glucosylated tetrahydrocurcumin. Drug Des. Dev. Ther. 2015, 9, 3579-3588. [CrossRef]

25. Osidak, E.O.; Kozhukhov, V.I.; Osidak, M.S.; Domogatsky, S.P. Collagen as bioink for bioprinting: A comprehensive review, Int. J. Bioprinting 2020, 6, 270. [CrossRef]

26. Andonegi, M.; Irastorza, A.; Izeta, A.; de la Caba, K.; Guerrero, P. Physicochemical and biological performance of aloe veraincorporated native collagen films. Pharmaceutics 2020, 12, 1273. [CrossRef]

27. Williamson, R.V. The Flow of Pseudoplastic Materials. Ind. Eng. Chem. 1929, 21, 1108-1111. [CrossRef]

28. Alvarez-Castillo, E.; Oliveira, S.; Bengoechea, C.; Sousa, I.; Raymundo, A.; Guerrero, A. A rheological approach to 3D printing of plasma protein based doughs. J. Food Eng. 2021, 288, 110255. [CrossRef]

29. Chaabra, R.P.; Richardson, F.J. Rheometry for non-newtonian fluids. In Non-Newtonian Flow in the Process Industries; Chaabra, R.P., Richardson, F.J., Eds.; Elsevier: Amsterdam, The Netherlands, 1999; pp. 37-72. [CrossRef]

30. Costa, P.; Lobo, J.M. Modeling and comparison of dissolution profiles. Eur. J. Pharm. Sci. 2001, 13, 123-133. [CrossRef]

31. Corker, A.; Ng, H.C.H.; Poole, R.J.; García-Tuñón, E. 3D printing with 2D colloids: Designing rheology protocols to predict "printability" of soft-materials. Soft Matter 2019, 15, 1444-1456. [CrossRef] [PubMed]

32. Zuidem, J.M.; Rivet, C.J.; Gilbert, R.J.; Morrison, F.A. A protocol for rheological characterization of hydrogels for tissue engineering strategies. J. Biomed. Mater. Res. 2013, 102, 1063-1073. [CrossRef]

33. Machado, A.A.S.; Martins, V.C.A.; Plepis, A.M.G. Thermal and rheological behavior of collagen. Chitosan blends. J. Therm. Anal. 2002, 67, 491-498. [CrossRef]

34. Yang, H.; Duan, L.; Li, Q.; Tian, Z.; Li, G. Experimental and modeling investigation on the rheological behavior of collagen solution as a function of acetic acid concentration. J. Mech. Behav. Biomed. Mater. 2018, 77, 125-134. [CrossRef]

35. Lille, M.; Nurmela, A.; Nordlund, E.; Metsä-Kortelainen, S.; Sozer, N. Applicability of protein and fiber-rich food materials in extrusion-based 3d printing. J. Food Eng. 2018, 220, 20-27. [CrossRef]

36. Wu, T.; Gray, E.; Chen, B. A self-healing, adaptive and conductive polymer composite ink for 3D printing of gas sensors. J. Mater. Chem. C 2018, 6, 6200-6207. [CrossRef]

37. Peralta, J.M.; Meza, B.E.; Zorrilla, S.E. Analytical solutions for the free-draining flow of a Carreau-Yasuda fluid on a vertical plate. Chem. Eng. Sci. 2017, 168, 391-402. [CrossRef]

38. Guo, C.; Zhang, M.; Devahastin, S. 3D extrusion-based printability evaluation of selected cereal grains by computational fluid dynamic simulation. J. Food Eng. 2020, 286, 110113. [CrossRef]

39. Moreira, R.; Chenlo, F.; Torres, M.D. Effect of shortenings on the rheology of gluten-free doughs: Study of chestnut flour with chia flour, olive and sunflower oils. J. Texture Stud. 2012, 43, 375-383. [CrossRef]

40. Torres, M.D.; Hallmark, B.; Wilson, D.I. Effect of concentration on shear and extensional rheology of guar gum solutions. Food Hydrocoll. 2014, 40, 85-95. [CrossRef]

41. Yang, F.; Guo, C.; Zhang, M.; Bhandari, B.; Liu, Y. Improving 3D printing process of lemon juice gel based on fluid flow numerical simulation. LWT-Food Sci. Technol. 2019, 102, 89-99. [CrossRef] 
42. Riaz, T.; Zeeshan, R.; Zarif, F.; Ilyas, K.; Muhammad, N.; Safi, S.Z.; Rahim, A.; Rizvi, S.A.A.; Rehman, I.U. FTIR analysis of natural and synthetic collagen. Appl. Spectrosc. Rev. 2018, 53, 703-746. [CrossRef]

43. Liao, W.; Guanghua, X.; Li, Y.; Shen, X.R.; Li, C. Comparison of characteristics and fibril-forming ability of skin collagen from barramundi (Lates calcarifer) and tilapia (Oreochromis niloticus). Int. J. Biol. Macromol. 2018, 107, 549-559. [CrossRef]

44. de Campos Vidal, B.; Mello, M.L.S. Collagen type I amide I band infrared spectroscopy. Micron 2011, 42, 283-289. [CrossRef]

45. Kaczmarek, B.; Sionkowska, A.; Skopinska-Wisniewska, J. Influence of glycosaminoglycans on the properties of thin films based on chitosan/collagen blends. J. Mech. Behav. Biomed. Mater. 2018, 80, 189-193. [CrossRef]

46. Bozec, L.; Odlyha, M. Thermal denaturation studies of collagen by microthermal analysis and atomic force microscopy. Biophys. J. 2011, 101, 228-236. [CrossRef] [PubMed]

47. Gauza-Włodarczyk, M.; Kubisz, L.; Mielcarek, S.; Włodarczyk, D. Comparison of thermal properties of fish collagen and bovine collagen in the temperature range 298-670 K. Mater. Sci. Eng. C-Mater. Biol. Appl. 2017, 80, 468-471. [CrossRef] [PubMed]

48. Schroepfer, M.; Meyer, M. DSC investigation of bovine hide collagen at varying degrees of crosslinking and humidities. Int. J. Biol. Macromol. 2017, 103, 120-128. [CrossRef] [PubMed]

49. Shi, D.; Liu, F.; Yu, Z.; Chang, B.; Goff, H.D.; Zhong, F. Effect of aging treatment on the physicochemical properties of collagen films. Food Hydrocoll. 2019, 87, 436-447. [CrossRef]

50. Valencia, G.A.; Luciano, C.G.; LourençO, R.V.; Bittante, A.M.Q.B.; Sobral, P.J.A. Morphological and physical properties of nano-biocomposite films base on collagen loaded with laponite ${ }^{\circledR}$. Food Packag. Shelf Life 2019, 19, 24-30. [CrossRef]

51. Zou, Y.; Wang, L.; Cai, P.; Li, P.; Zhang, M.; Sun, Z.; Sun, C.; Xu, W.; Wang, D. Effect of ultrasound assisted extraction on the physicochemical and functional properties of collagen from soft-shelled turtle calipash. Int. J. Biol. Macromol. 2017, 105, 1602-1610. [CrossRef]

52. Trivedi, M.K.; Gangwar, M.; Mondal, S.C.; Jana, S. Protective effects of tetrahydrocurcumin (THC) on fibroblast and melanoma cell lines in vitro: It's implication for wound healing. J. Food Sci. Technol.-Mysore 2017, 54, 1137-1145. [CrossRef]

53. Kezwon, A.; Góral, I.; Wojciechowski, K. Effect of surfactants on surface active and rheological properties of type I collagen at air/water interface. Colloid Surf. B-Biointerfaces 2016, 148, 238-248. [CrossRef]

54. Adriani, N.H.; Rahayu, D.U.C.; Saepudin, E. Activity of hydrogenated curcuminoid on Pd/C catalyst and its antibacterial activity against Staphylococcus aureus and Streptococcus mutans. IOP Conf. Ser. Mater. Sci. Eng. 2020, 902, 012068. [CrossRef]

55. Castellan, A.; Ruggiero, R.; da Silva, L.G.; Portes, E.; Grelier, S.; Gardrat, C. Photophysics and photochemistry of tetrahydrocurcuminoids. J. Photochem. Photobiol. A-Chem. 2007, 190, 110-120. [CrossRef]

56. Abubakr, N.; Lin, S.X.; Chin, X.D. Effects of drying methods on the release kinetics of vitamin B12 in calcium alginate beads. Dry. Technol. 2009, 27, 1258-1265. [CrossRef]

57. Supramaniam, J.; Adnan, R.; Kaus, N.H.M.; Bushra, R. Magnetic nanocellulose alginate hydrogel beads as potential drug delivery system. Int. J. Biol. Macromol. 2018, 118, 640-648. [CrossRef] [PubMed]

58. Vigata, M.; Meinert, C.; Hutmacher, D.W.; Bock, N. Hydrogels as drug delivery systems: A review of current characterization and evaluation techniques. Pharmaceutics 2020, 12, 1188. [CrossRef]

59. Boddupalli, B.M.; Mohammed, Z.N.K.; Nath, R.A.; Banji, D. Mucoadhesive drug delivery system: An overview. J. Adv. Pharm. Technol. Res. 2010, 1, 381-387. [CrossRef]

60. Thirawong, N.; Nunthanid, J.; Puttipipatkhachorn, S.; Sriamornsak, P. Mucoadhesive properties of various pectins on gastrointestinal mucosa: An in vitro evaluation using texture analyzer. Eur. J. Pharm. Biopharm. 2007, 67, 132-140. [CrossRef]

61. Soe, M.T.; Chitropas, P.; Pongjanyakul, T.; Limpongsa, E.; Jaipakdee, N. Thai glutinous rice starch modified by ball milling and its application as a mucoadhesive polymer. Carbohydr. Polym. 2020, 232, 115812. [CrossRef]

62. Bassi da Silva, J.; Ferreira, S.B.D.S.; Reis, A.V.; Cook, M.T.; Bruschi, M.L. Assessing mucoadhesion in polymer gels: The effect of method type and instrument variables. Polymers 2018, 10, 254. [CrossRef] [PubMed] 